Supporting information

\title{
Electro-responsive Supramolecular Graphene Oxide Hydrogels for Active Bacteria Adsorption and Removal
}

\author{
Bin Xue, ${ }^{\dagger}$ Meng Qin, ${ }^{\dagger}$ Junhua Wu, ${ }^{\ddagger}$ Dongjun Luo, ${ }^{\perp}$ Qing Jiang, ${ }^{\ddagger}$ Ying Li ${ }^{*}, " ~ Y i$ \\ Cao*, ${ }^{\dagger}$ and Wei Wang* ${ }^{\dagger}$
}

${ }^{\dagger}$ National Laboratory of Solid State Microstructure, Department of Physics, Nanjing University 22 Hankou Road, Nanjing, Jiangsu, China

${ }^{*}$ Jiangsu Key Laboratory of Molecular Medicine, Medical School, Nanjing University, 22 Hankou Road, Nanjing, Jiangsu, 210093, P.R. China

" Jiangsu Engineering Technology Research Centre of Environmental Cleaning Materials, Jiangsu Key Laboratory of Atmospheric Environment Monitoring and Pollution Control, Jiangsu Joint Laboratory of Atmospheric Pollution Control, Collaborative Innovation Center of Atmospheric Environment and Equipment Technology, School of Environmental Science and Engineering, Nanjing University of Information Science \& Technology, 219 Ningliu Road, Nanjing, Jiangsu, 210044, P.R. China

${ }^{\perp}$ Department of Hepatobiliary Surgery, Nanjing Drum Tower Hospital Clinical College of Nanjing Medical University, 321 Zhong Shan North Road, Nanjing, Jiangsu, 210008, P.R. China

E-mail: caoyi@nju.edu.cn, yingliubc@gmail.com orwangwei@nju.edu.cn 


\section{Experimental methods :}

Materials: $\quad \operatorname{Tris}(2,2$ '-bipyridyl)dichlororuthenium(II) hexahydrate, dichlorotris(1,10-phenanthroline)ruthenium(II) hydrate and cytotoxicity detection kit (MTT and LDH) were purchased from Sigma-Aldrich. Tris(4,7-diphenyl-1,10-phenanthroline) ruthenium(II) dichloride was purchased from Aladdin. GO was received as a generous gift from the Yu Lab in USTC. All chemicals were used without further purification.

The accumulated bacteria removal efficiency: The sample hydrogel was used for catch-and-release cycles (See above section for experimental details) in the same bacteria solution for three times to estimated the accumulated bacteria removal efficiency. The percentage of adsorbed bacteria was calculated as the change of the $\mathrm{OD}_{600 \mathrm{~nm}}$ after three cycles of purification divided by the initial $\mathrm{OD}_{600 \mathrm{~nm}}$ of the solution.

The growth activity of the bacteria: The adsorbed bacteria and bacteria with electric treatment were rinsed off from the hydrogel with PBS. Both E.coli and SAU were incubated in the LB media at $37^{\circ} \mathrm{C}$ in orbital shakers at $225 \mathrm{rpm}$. OD at $600 \mathrm{~nm}$ was measured to monitor the growth of bacteria.

The toxicity of GO and $\mathbf{R u}(\mathrm{II})$ to different bacteria: The bacteria (E. coli or $S A U$ ) solution $\left(5 \mu \mathrm{L}, \mathrm{OD}_{600}=0.6\right)$ was added into the LB solutions $(5 \mathrm{~mL})$ which contained different concentrations of $\mathrm{GO}$ or $\mathrm{Ru}(\mathrm{II})$. Control groups without $\mathrm{GO}$ and $\mathrm{Ru}(\mathrm{II})$ were also prepared. All the groups were placed in orbital shakers at $37{ }^{\circ} \mathrm{C}$ for $12 \mathrm{~h}$. The concentrations of bacteria were monitored by OD at $600 \mathrm{~nm}$. The percentage of bacteria viability was calculated as follows: $\frac{A_{\text {drug }}-A_{\text {blank }}}{A_{\text {control }}-A_{\text {blank }}} \times 100 \%$.

In vivo toxicity tests: Four-week-old female ICR mice (Laboratory Animal Center of the Academy of Military Medical Science, Beijing, China) were used in in vivo toxicity tests. The animal experiments were conducted according to the Regulation on Experimental Animals of Nanjing University. All the treated mice were randomly divided into 6 groups $(\mathrm{n}=5)$. The solubility of $\mathrm{Ru}(\mathrm{II})$ in water is $40 \mathrm{mg} \mathrm{mL}^{-1}$ and the maximum volume can be used for a mouse is $500 \mu \mathrm{L} / 20 \mathrm{gBW}$. So we used 500 
$\mu \mathrm{L} / 20 \mathrm{gBWV}$ dose of $40 \mathrm{mg} \mathrm{mL}^{-1} \mathrm{Ru}$ (II) solution for the vivo toxicity test. The control groups (i.g. with water) and experiment groups (i.g. with $\mathrm{Ru}(\mathrm{II})$ ) were killed by breaking their necks and dissected at the time as indicated in Figure S22.

The adsorption of $L X 2$ cells with $G O / R u(I I)$ and GO/Ru(III) hydrogel: These cells were grown in RPMI 1640 medium with $10 \%$ FBS in the presence of $100 \mathrm{U}$ $\mathrm{mL}^{-1}$ penicillin and $100 \mu \mathrm{g} \mathrm{mL}^{-1}$ streptomycin and maintained at $37^{\circ} \mathrm{C}$ in a humidified atmosphere containing $5 \%(\mathrm{v} / \mathrm{v}) \mathrm{CO}_{2}$. The hydrogel were added into the cell suspensions and the number of cells was directly counted before and after the adsorption process under the field of an optical microscope (LWD300-38LT, Cewei, China).

The cytotoxicity of GO and Ru(II) in LX2 and $3 T 3$ cells: $L X 2$ and $3 T 3$ cells were seeded in a 24 -well plate at a density of $1 \times 10^{4}$ cells per well (with $1.0 \mathrm{~mL}$ DMEM medium). After $24 \mathrm{~h}$ incubation, $20 \mu \mathrm{L}$ of $\mathrm{GO}$ or $\mathrm{Ru}(\mathrm{II})$ solution was added to the wells with cells. Then all the cells were cultured for additional $48 \mathrm{~h}$. The cell viability was assessed by the MTT method. Firstly, cells were incubated with MTT (0.5 mg $\mathrm{mL}^{-1}$ ) for $4 \mathrm{~h}$ at $37^{\circ} \mathrm{C}$. During this incubation period, water-insoluble formazan crystals were formed, which were dissolved by the addition of $100 \mu \mathrm{L}$ DMSO per well. The optical densities at $570 \mathrm{~nm}$ were measured using an enzyme-linked immunosorbent assay plate reader. Wells containing culture medium and MTT but no cells acted as blanks. The percentage of cell viability was calculated as follows: $\frac{A_{\text {drug }}-A_{\text {blank }}}{A_{\text {control }}-A_{\text {blank }}} \times 100 \%$.

The LDH release measurement: The LDH released from bacteria was measured using a standard LDH Cytotoxicity Assay Kit (Sigma-Aldrich). The desorbed bacteria and electrically deactivated bacteria suspensions were centrifuged at a speed of $6000 \mathrm{rpm}$ for $5 \mathrm{~min}$ and then the supernatant was taken out and mixed with the testing solution (containing 2-p-iodophenyl-3-nitrophenyl tetrazolium chloride, diaphorase and lactic acid) at the volume ratio of 2:1 (supernatant: the testing solution). The bacteria solution treated with $10 \%(\mathrm{v} / \mathrm{v}) \mathrm{LDH}$ releasing agent was used as the positive control and prepared with the same procedure as that for the desorbed 
bacteria and electrically deactivated bacteria. All solutions were incubated for $1 \mathrm{~h}$ at $37^{\circ} \mathrm{C}$ in an orbital shaker.

Then a V-550 (JASCO Inc., Japan) spectrophotometer was used to quantify the released LDH by monitoring the UV-Vis absorbance at $490 \mathrm{~nm}$.

Scanning electron microscope (SEM): SEM images were obtained using a Quanta Scanning Electron Microscope (Quata 200, FEI) at $20 \mathrm{kV}$. The hydrogels were lyophilized prior to the measurement.

UV-Vis spectroscopy: UV-Vis spectra of all samples were recorded using a V-550 (JASCO Inc., Japan) spectrophotometer. The cuvette width was $1 \mathrm{~cm}$ and the bandwidth was set as $0.2 \mathrm{~nm}$.

Fluorescence spectroscopy: Spectrofluorometric experiments were performed using an FP-6500 (JASCO Inc., Japan). The emission spectra were measured using an excitation wavelength of $365 \mathrm{~nm}$.

Mechanical Measurements: The hydrogels were carefully transferred to the rheometer plate of the Thermo Scientific Haake RheoStress 6000 with a spatula prior to the measurement. The rheology experiments were then carried out using a strain-sweep mode with a strain amplitude range of $0.01 \%$ to $100 \%$ at $1 \mathrm{~Hz}$ as shown in Figure S2 and a frequency-sweep mode with frequency of $0.01 \mathrm{~Hz}$ to $100 \mathrm{~Hz}$ at $0.1 \%$ strain as in Figure 2 (geometry: $1^{\circ} / 20 \mathrm{~mm}$ of cone and plate; gap: $0.37 \mathrm{~mm}$; temperature: $20^{\circ} \mathrm{C}$ ). The variable temperature experiments were carried out in the temperature mode at stain of $0.1 \%$ and frequency of $1 \mathrm{~Hz}$.

Cyclic voltammogram (CV): A 3-electrode system was used to obtain cyclic and linear sweep voltammograms; a glassy carbon electrode (working electrode), $\mathrm{Ag} / \mathrm{AgCl}$ (reference electrode), and a platinum wire (counter electrode) were connected to an electrochemical workstation with a scan rate of $100 \mathrm{mV} \mathrm{s}^{-1}$. The samples were $\mathrm{GO} / \mathrm{Ru}$ hydrogels including $\mathrm{GO} / \mathrm{Ru}(\mathrm{II})$ and $\mathrm{GO} / \mathrm{Ru}(\mathrm{III})$ as well as the GO solution. The concentrations of $\mathrm{Ru}$ and $\mathrm{GO}$ in the samples were $0.025 \mathrm{mg} \mathrm{mL}^{-1}$ and $0.25 \mathrm{mg} \mathrm{mL}^{-1}$.

Chronoamperometry: Chronoamperometry also used the 3-electrode system as the $\mathrm{CV}$ experiments. The volumes of $\mathrm{GO} / \mathrm{Ru}(\mathrm{II})$ and $\mathrm{GO} / \mathrm{Ru}(\mathrm{III})$ hydrogels were both 0.4 
$\mathrm{cm}^{3}$. The potential during the oxidation and reduction were $+2 \mathrm{~V}$ and $-1.2 \mathrm{~V}$, respectively.

Zeta potential: The zeta potential measurements were conducted in PBS buffer, the same buffer as we used for bacteria catch and release experiments, to minimize the effect of $\mathrm{pH}$, ionic strength and other factors on the measured zeta potentials. Typically, $100 \mathrm{uL}$ of hydrogels were suspended in $900 \mathrm{uL}$ of PBS buffer and fractured by a vortex mixer (Scientific Instruments, USA) for $15 \mathrm{~min}$ at its maximum power. Then the zeta potential of the hydrogel suspension was measured by the Zetasizer Nano ZS (Malvern, UK). The same hydrogels were measured for at least three times to guarantee the reproducibility.

The test of bacteria-killing effects using agar plates: Agar plates were prepared and inoculated with $150 \mu \mathrm{L}$ of different bacteria solutions before and after electric deactivation. Two different bacteria concentrations $\left(\mathrm{OD}_{600}=0.6\right.$ and $\left.\mathrm{OD}_{600}=0.2\right)$ were used for the experiments. The agar plates were allowed to grow for $12 \mathrm{~h}$ at $37^{\circ} \mathrm{C}$ in an incubator and then imaged.

FT-IR measurement for the hydrogels: All the FT-IR samples were prepared by lyophilization of the hydrogels prior to the measurement. FT-IR data was recorded in a Fourier Transform Infrared spectrometer (NEXUS870, NICOLET).

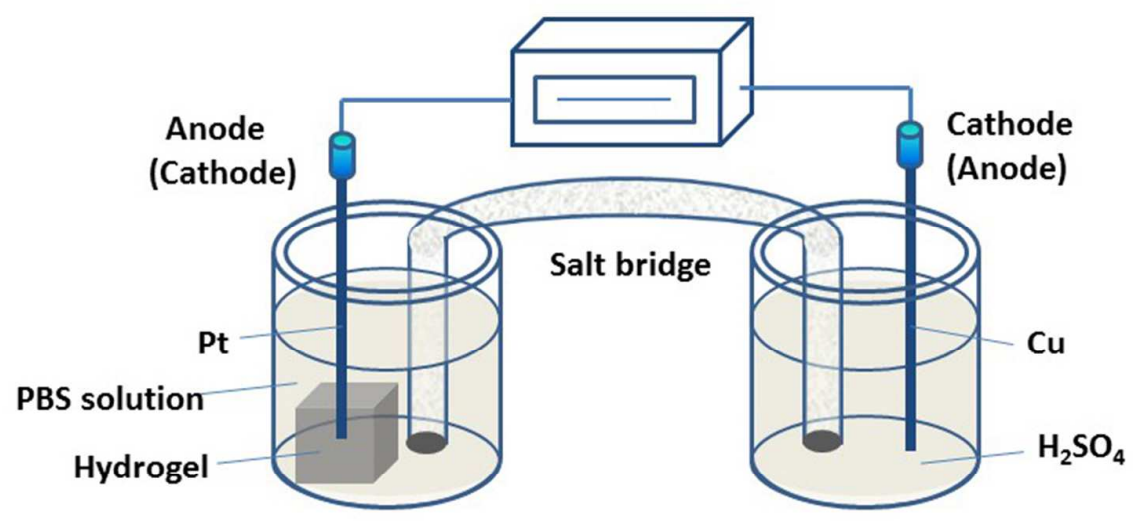


Figure S1. Schematic diagram of the electrochemical cell for the electro-oxidation of the hydrogel.
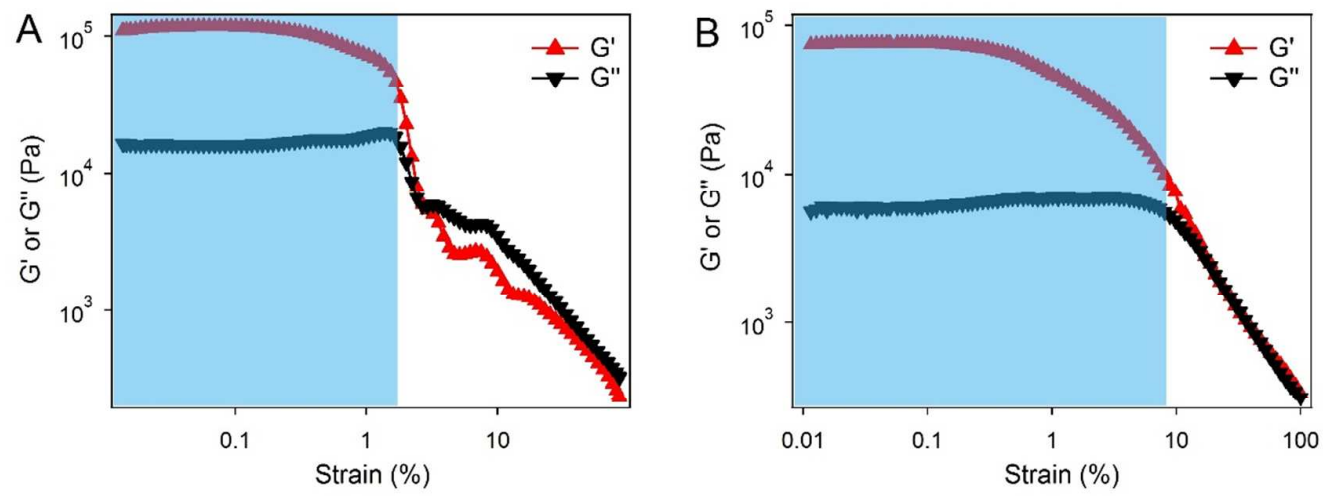

Figure S2. The strain sweep experiments for the $\mathrm{GO} / \mathrm{Ru}$ hydrogels. (A) The strain-sweep experiment of the $\mathrm{GO} / \mathrm{Ru}$ (II) at a constant sweep frequency of $1 \mathrm{~Hz}$. (B) The strain-sweep experiment of the $\mathrm{GO} / \mathrm{Ru}$ (III) hydrogel at a constant sweep frequency of $1 \mathrm{~Hz}$. The linear viscoelastic (LVE) regions are highlighted in light blue.
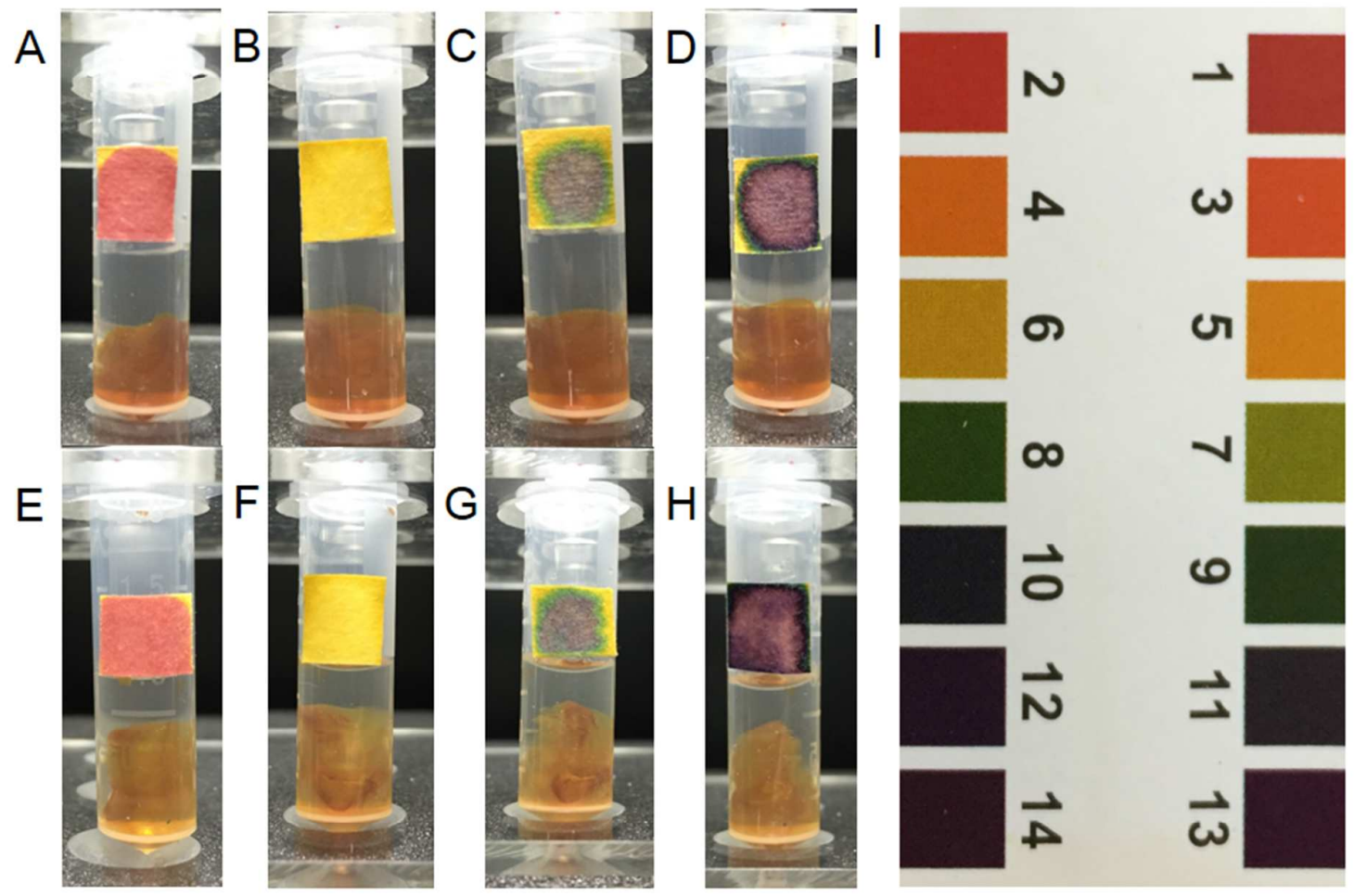

Figure S3. The stability of $\mathrm{GO} / \mathrm{Ru}$ hydrogels against different $\mathrm{pHs}$. The solution was PBS adjusted by $\mathrm{HCl}$ and $\mathrm{NaOH}$. GO/Ru(II) hydrogel (A-D) and $\mathrm{GO} / \mathrm{Ru}$ (III) hydrogel 
$(\mathrm{E} \sim \mathrm{H})$ were immersed in solutions at different $\mathrm{pH}(2 \sim 14)$. I is a $\mathrm{pH}$ test standard colorimetric card.
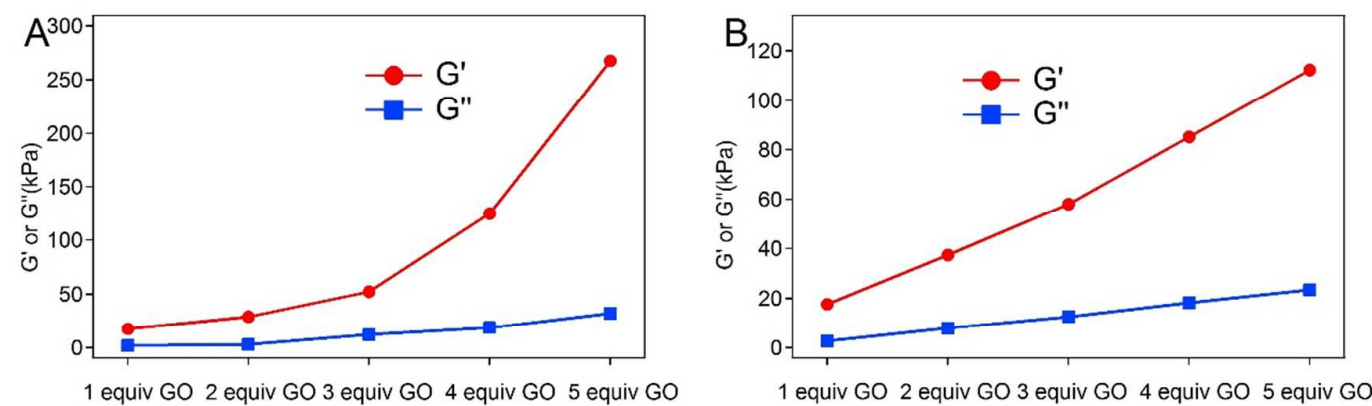

Figure S4. (A) The rheological properties of the hydrogels with different amounts of GO while the concentration of $\mathrm{Ru}(\mathrm{II})$ remained $0.25 \mathrm{mg} \mathrm{mL}^{-1}$. 1 equiv $\mathrm{GO}$ means 0.6 $\mathrm{mg} \mathrm{mL}^{-1}$ GO. (B) The rheological properties of the hydrogels with different amounts of $\mathrm{Ru}$ (II) while the concentration of $\mathrm{GO}$ was $2.5 \mathrm{mg} \mathrm{mL}^{-1}$, and 1 equiv $\mathrm{Ru}(\mathrm{II})$ is 0.06 $\mathrm{mg} \mathrm{mL} L^{-1}$.
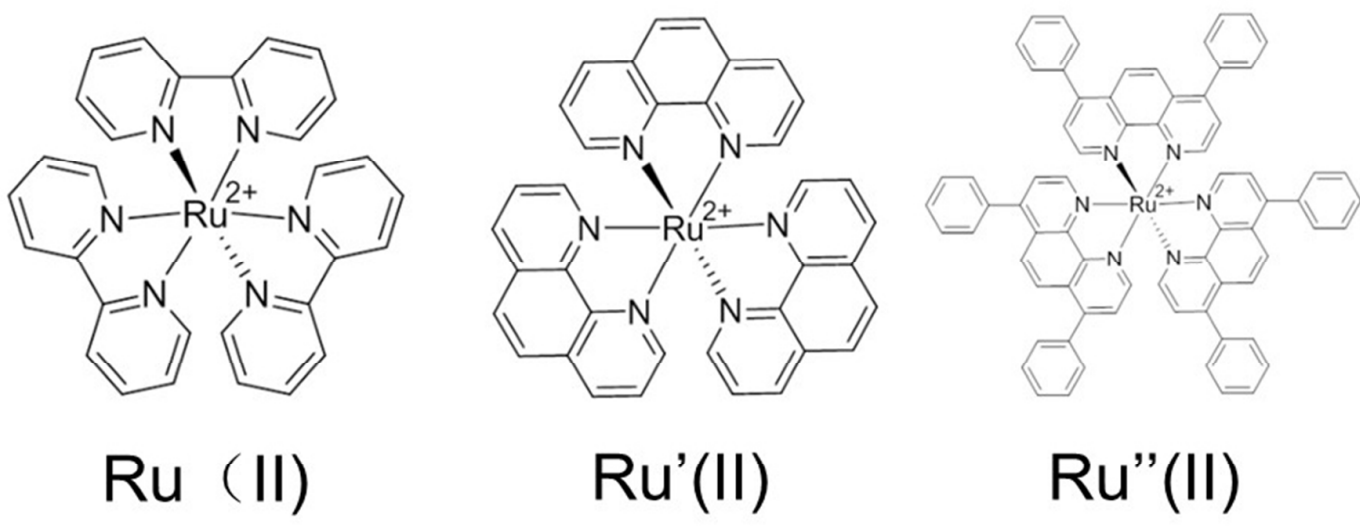

Ru"(II)

Figure S5. Chemical structures of ruthenium (II) complexes. 


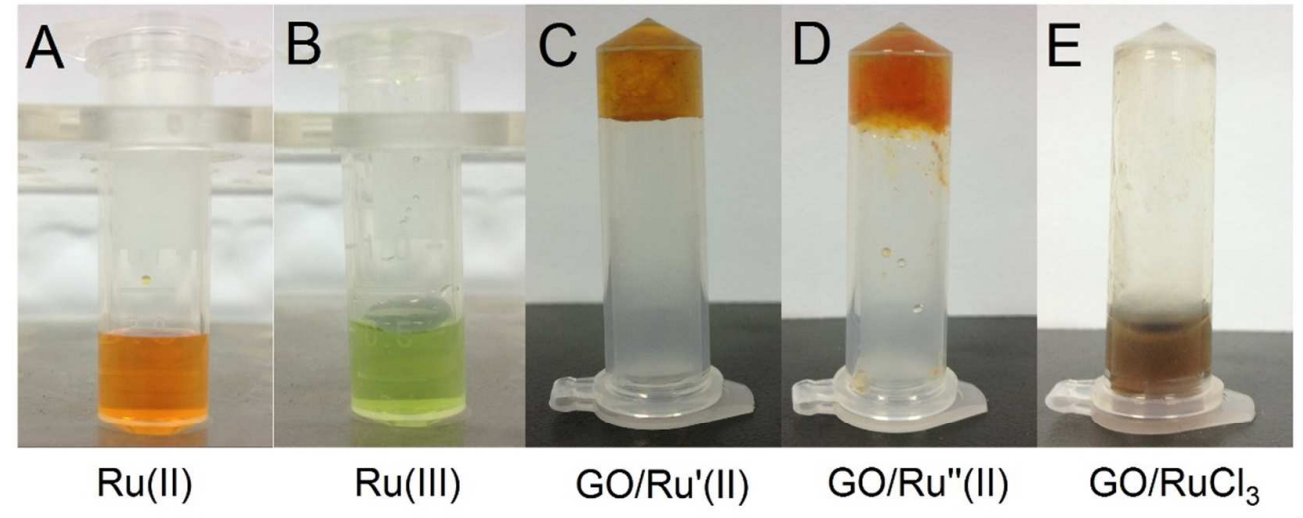

Figure S6. Images of Ru solutions and GO/Ru hydrogels. (A) Ru (II) solution (1 mg $\left.\mathrm{mL}^{-1}\right)$; (B) $\mathrm{Ru}(\mathrm{III})$ solution (1 $\mathrm{mg} \mathrm{mL}^{-1}$, oxidized from $\mathrm{Ru}(\mathrm{II})$ solution by electrolysis); (C) $\mathrm{GO} / \mathrm{Ru}^{\prime}(\mathrm{II})$; (D) $\mathrm{GO} / \mathrm{Ru}$ '(II); and (E) $\mathrm{GO} / \mathrm{RuCl}_{3}$. 

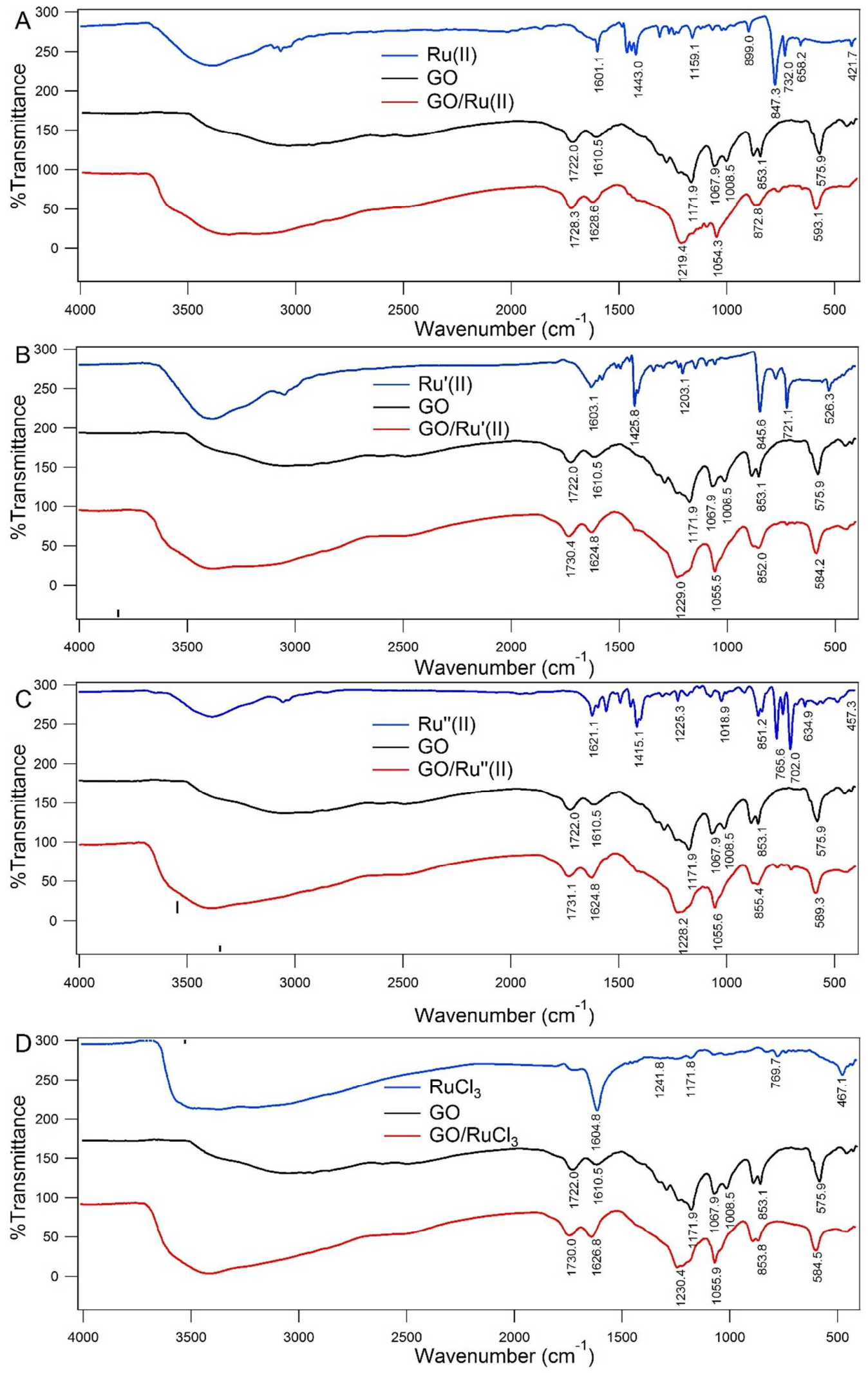
Figure S7. FT-IR of GO, ruthenium complex and the mixtures of both. The peaks in the range of $600 \mathrm{~cm}^{-1}$ and $800 \mathrm{~cm}^{-1}$ from the vibration of the ligands in $\mathrm{Ru}, \mathrm{Ru}$ ' and $\mathrm{Ru}$ ' are disappeared when interacting with GO.

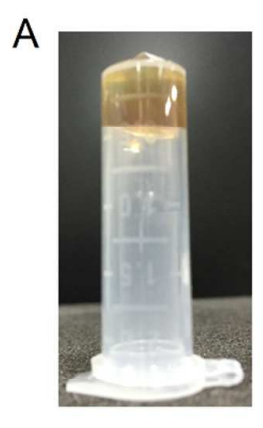

i

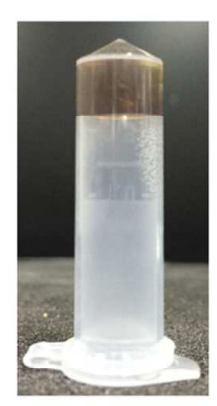

ii
B

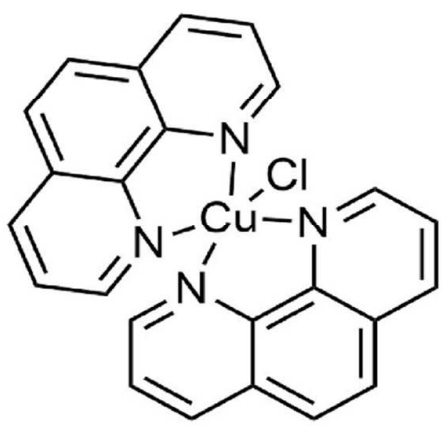

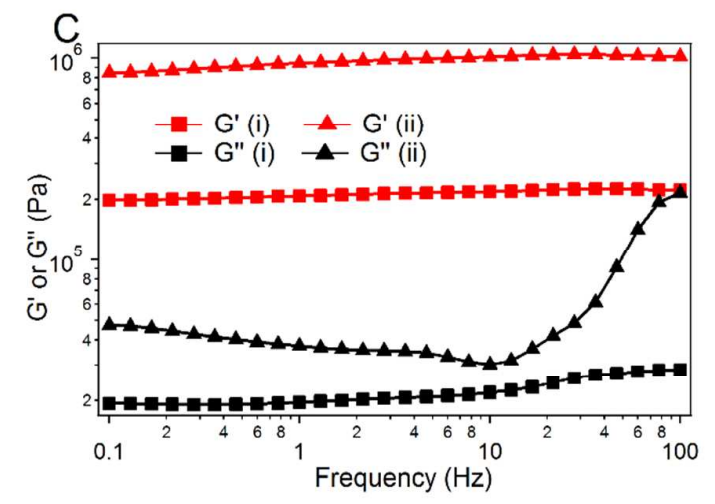

Figure S8. Hydrogels formed by GO and a copper complex. (A) Optical graphs of $\mathrm{GO} / \mathrm{Cu}(\mathrm{II})$ hydrogel. The concentrations of $\mathrm{GO}$ were $2.5 \mathrm{mg} \mathrm{mL}^{-1}$ (i) and $5 \mathrm{mg} \mathrm{mL}^{-1}$ (ii). The concentrations of copper complex were all $0.25 \mathrm{mg} \mathrm{mL}^{-1}$. (B) Chemical structure of the copper complex. (C) The rheological properties of $\mathrm{GO} / \mathrm{Cu}$ (II) at $0.1 \%$ strain in the frequency range of $0 \sim 100 \mathrm{~Hz}$. 

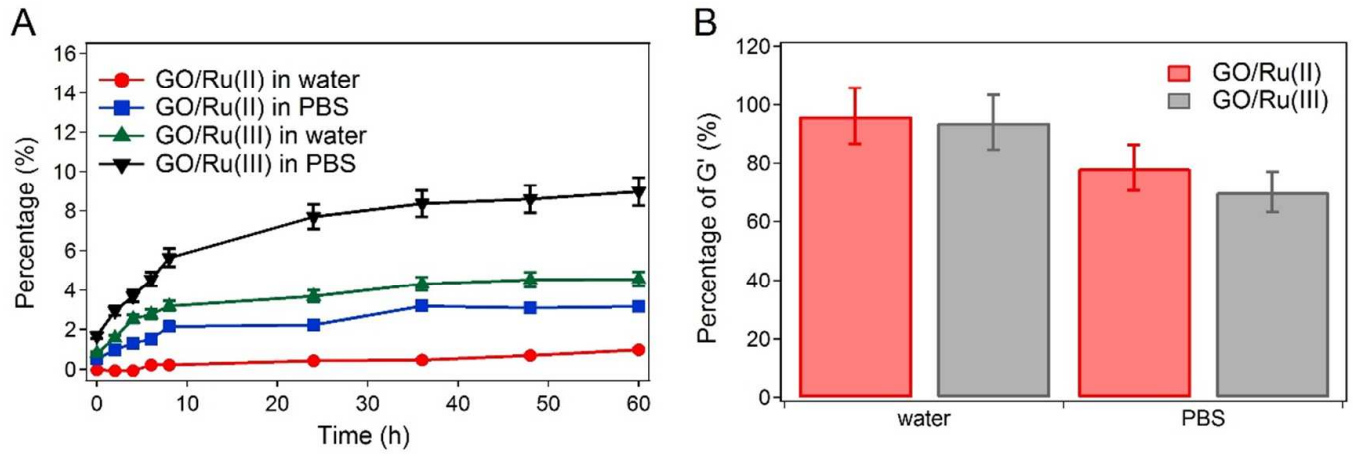

Figure S9. The ion release and mechanical properties change of the GO/Ru(II) and $\mathrm{GO} / \mathrm{Ru}$ (III) in $60 \mathrm{~h}$. (A) The ruthenium ion release from the hydrogel in a time period of $60 \mathrm{~h}$ in PBS and deionized water. (B) The normalized mechanical properties of $\mathrm{GO} / \mathrm{Ru}(\mathrm{II})$ and $\mathrm{GO} / \mathrm{Ru}(\mathrm{III})$ hydrogels after 60 -h incubation in PBS and deionized water compared to the original $\mathrm{GO} / \mathrm{Ru}(\mathrm{II})$ and $\mathrm{GO} / \mathrm{Ru}(\mathrm{III})$ hydrogels.
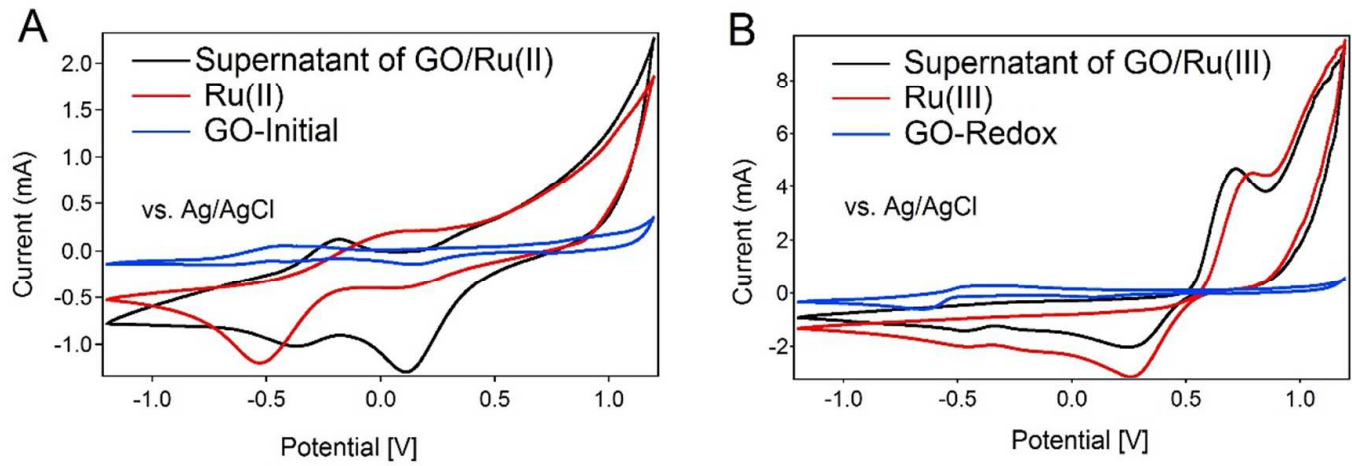

Figure S10. Cyclic voltammograms of the hydrogels. (A) Typical cyclic voltammograms of $\mathrm{Ru}(\mathrm{II})$, supernatant of $\mathrm{GO} / \mathrm{Ru}(\mathrm{II})$ hydrogel and the initial GO solution. (B) Typical cyclic voltammograms of $\mathrm{Ru}(\mathrm{III})$, supernatant of $\mathrm{GO} / \mathrm{Ru}(\mathrm{III})$ hydrogel and the GO solution after being electrolyzed once. 


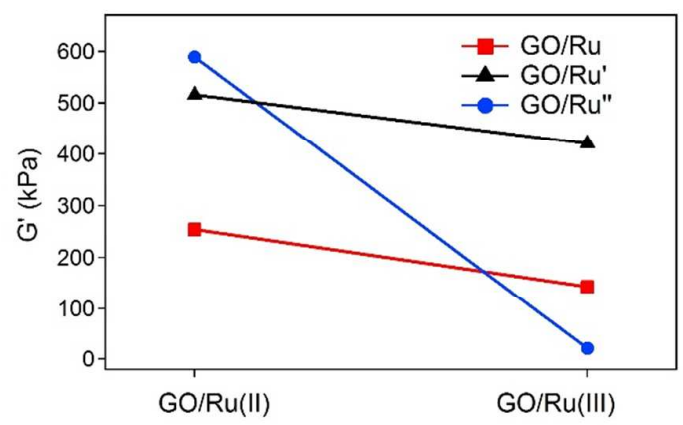

Figure S11. Rheological properties change using different ruthenium complexes. The concentration of GO was $2.5 \mathrm{mg} \mathrm{mL}^{-1}$ and that of ruthenium was $0.25 \mathrm{mg} \mathrm{mL}^{-1}$.

A

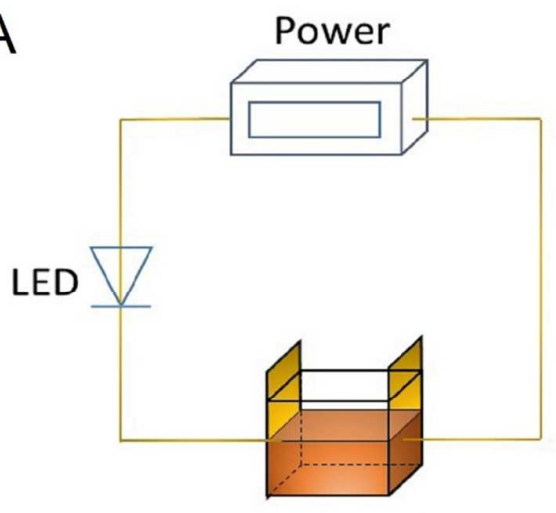

Hydrogel
B

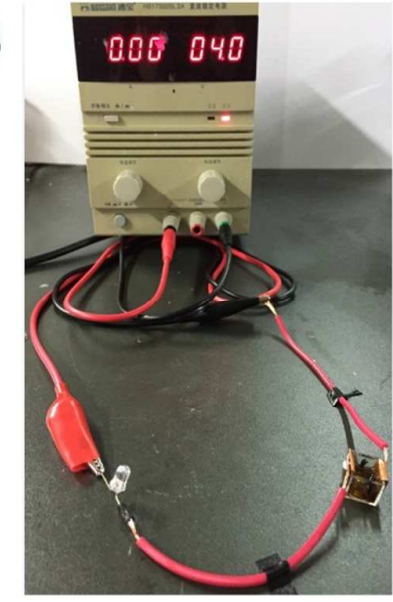

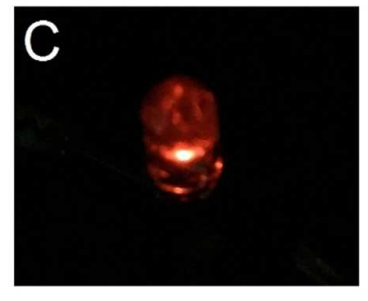

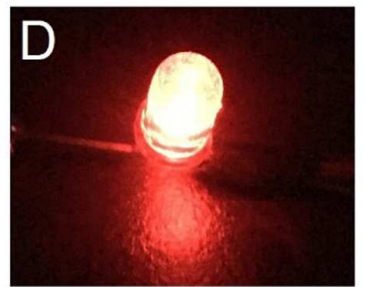

Figure S12. GO/Ru hydrogel as a controllable resistor. (A) The schematic of the electric circuit. An LED light bulb is used to visualize the change of the current in the circuit. (B) The optical image of the electric circuit. (C) and (D)The optical images of the LED bulb taken in a dark room using $\mathrm{GO} / \mathrm{Ru}(\mathrm{II})$ and $\mathrm{GO} / \mathrm{Ru}(\mathrm{III})$ as the controllable resistors, respectively. 

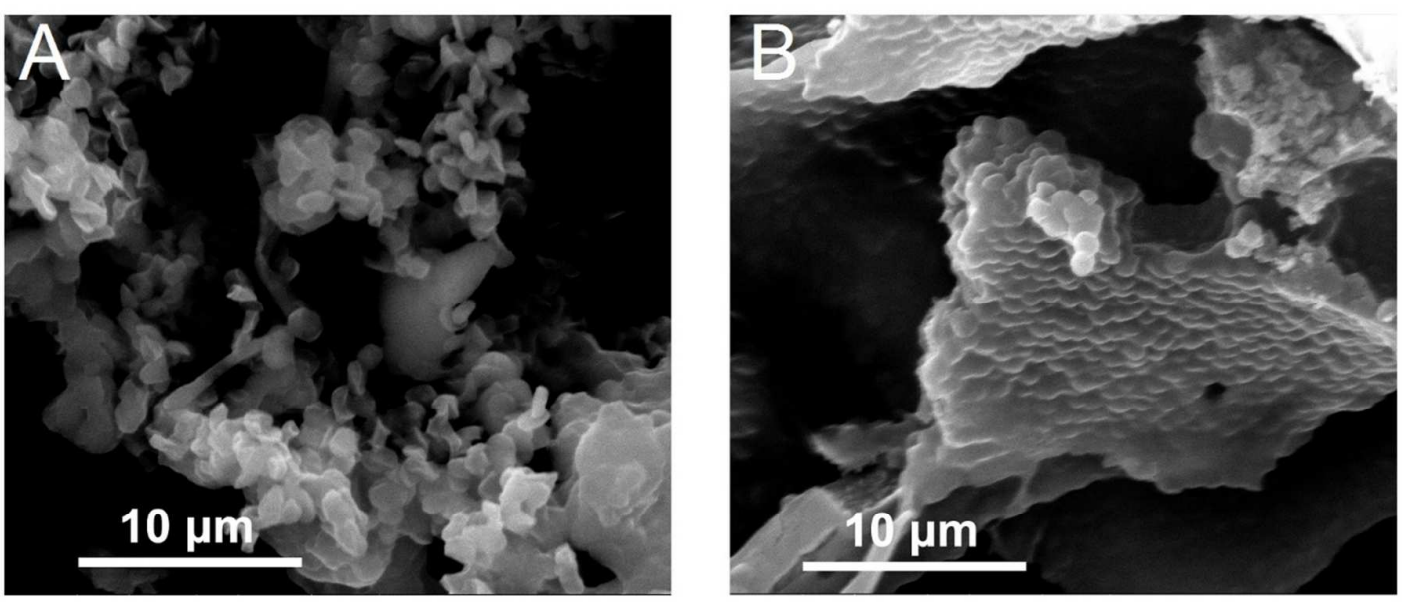

Figure S13. (A) SEM images of E. coli. (B) SEM images of $S A U$.
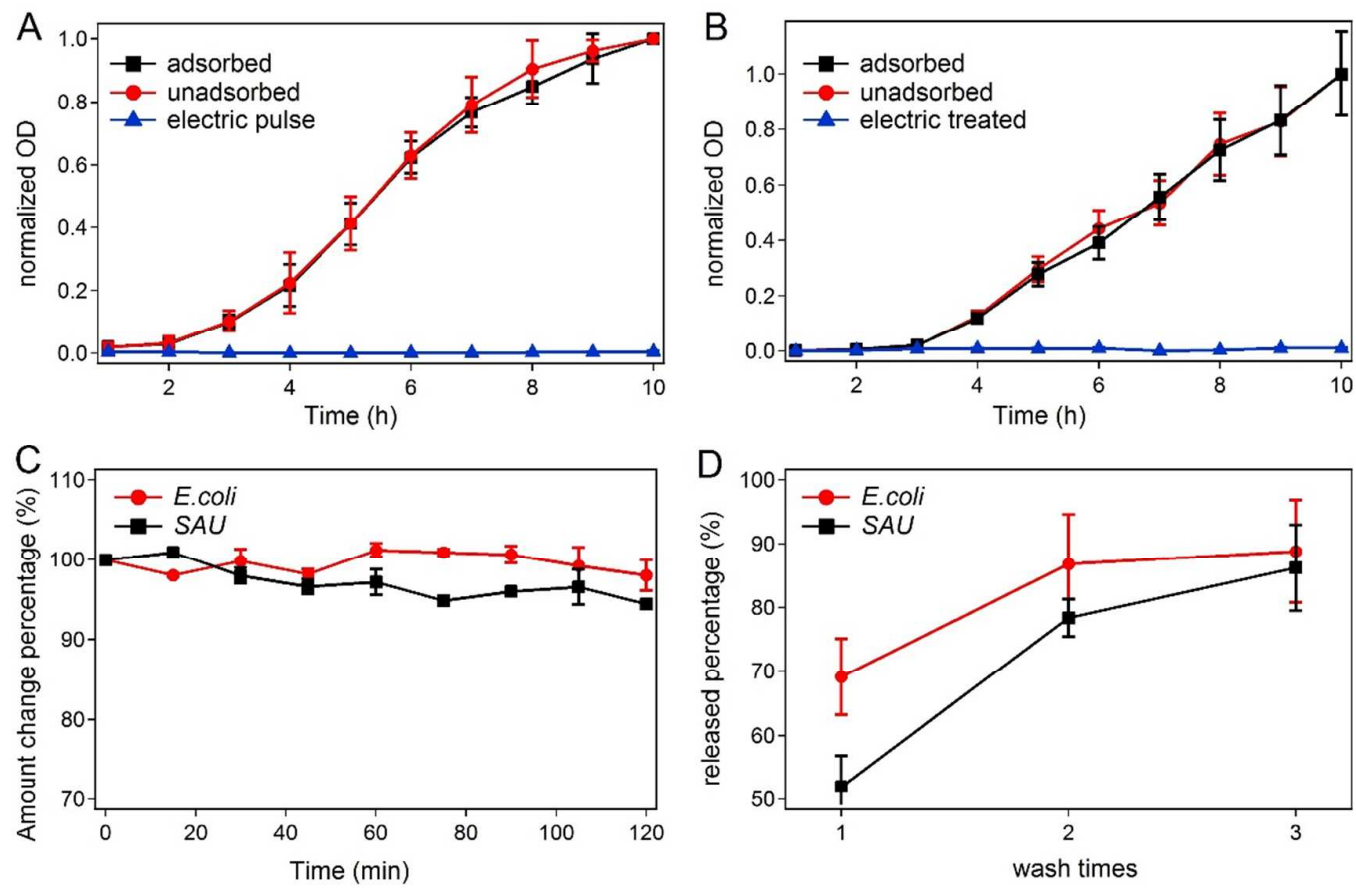

Figure S14. (A) The growth curves of the E. coli adsorbed and unadsorbed by the $\mathrm{GO} / \mathrm{Ru}$ (II) hydrogel as well as the E. coli treated with electric pluses. (B) The growth curves of the $S A U$ adsorbed and unadsorbed by the $\mathrm{GO} / \mathrm{Ru}$ (II) hydrogel as well as the SAU treated by electric pluses. (C) The growth of both E. coli and SAU in PBS during a period of two hours. (D) The percentages of released E. coli and SAU after different wash times. 

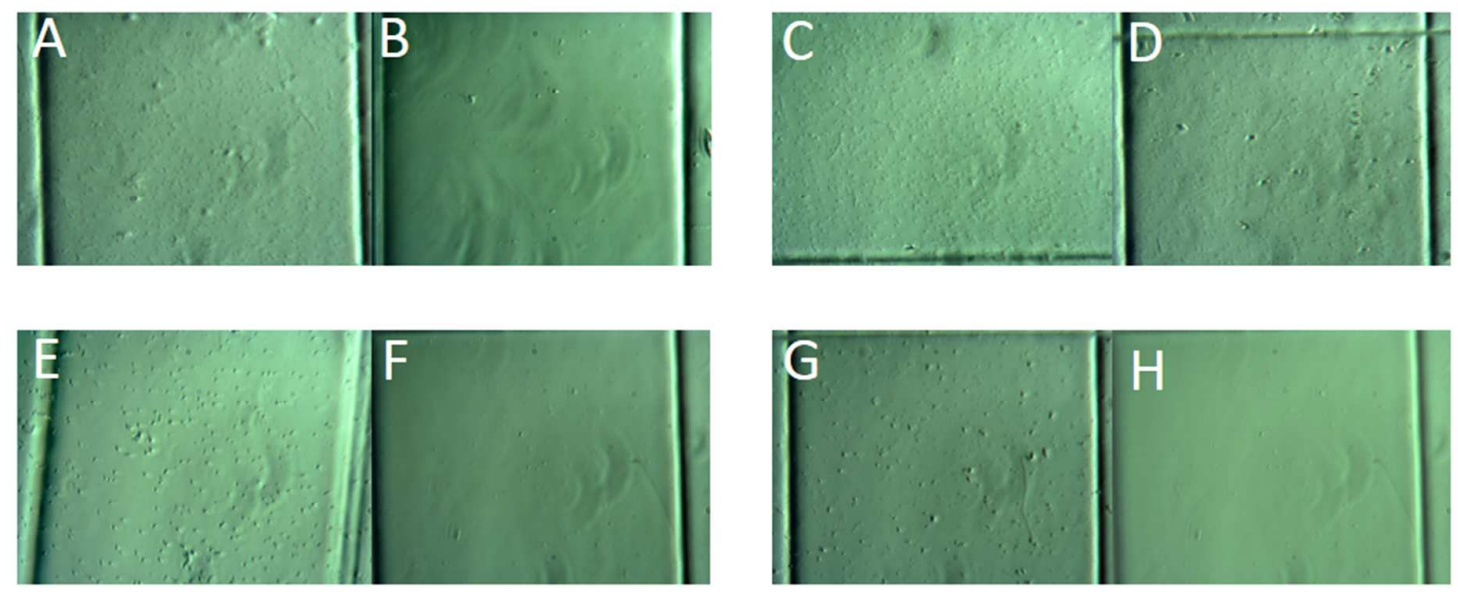

Figure S15. Microscopic images of hydrogels adsorbing E. coli. E. coli solution before (A) and after (B) adsorption using $\mathrm{GO} / \mathrm{Ru}(\mathrm{II})$. (82\% E. coli were removed.) The microscopic pictures of the E. coli solution before (C) and after (D) adsorption using $\mathrm{GO} / \mathrm{Ru}(\mathrm{III})$. (5\% E. coli were removed.) The microscope pictures of the $S A U$ solution before (E) and after (F) adsorption using $\mathrm{GO} / \mathrm{Ru}(\mathrm{II})$. (92\% $S A U$ were removed.) The microscopic pictures of the $S A U$ solution before $(\mathrm{G})$ and after $(\mathrm{H})$ adsorption using $\mathrm{GO} / \mathrm{Ru}(\mathrm{III})$. (95\% $S A U$ were removed.)

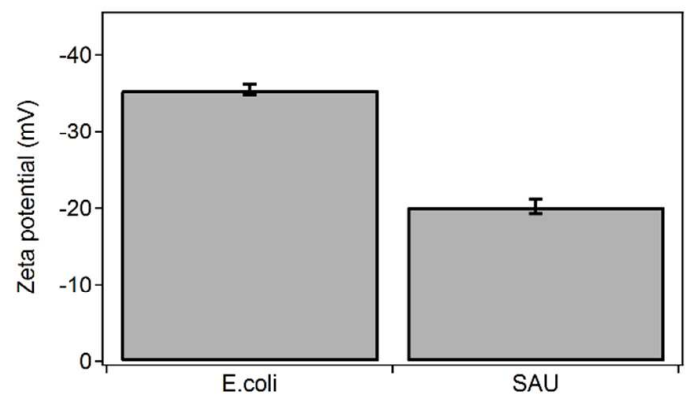

Figure S16. Zeta potentials of the E. coli and $S A U$. 

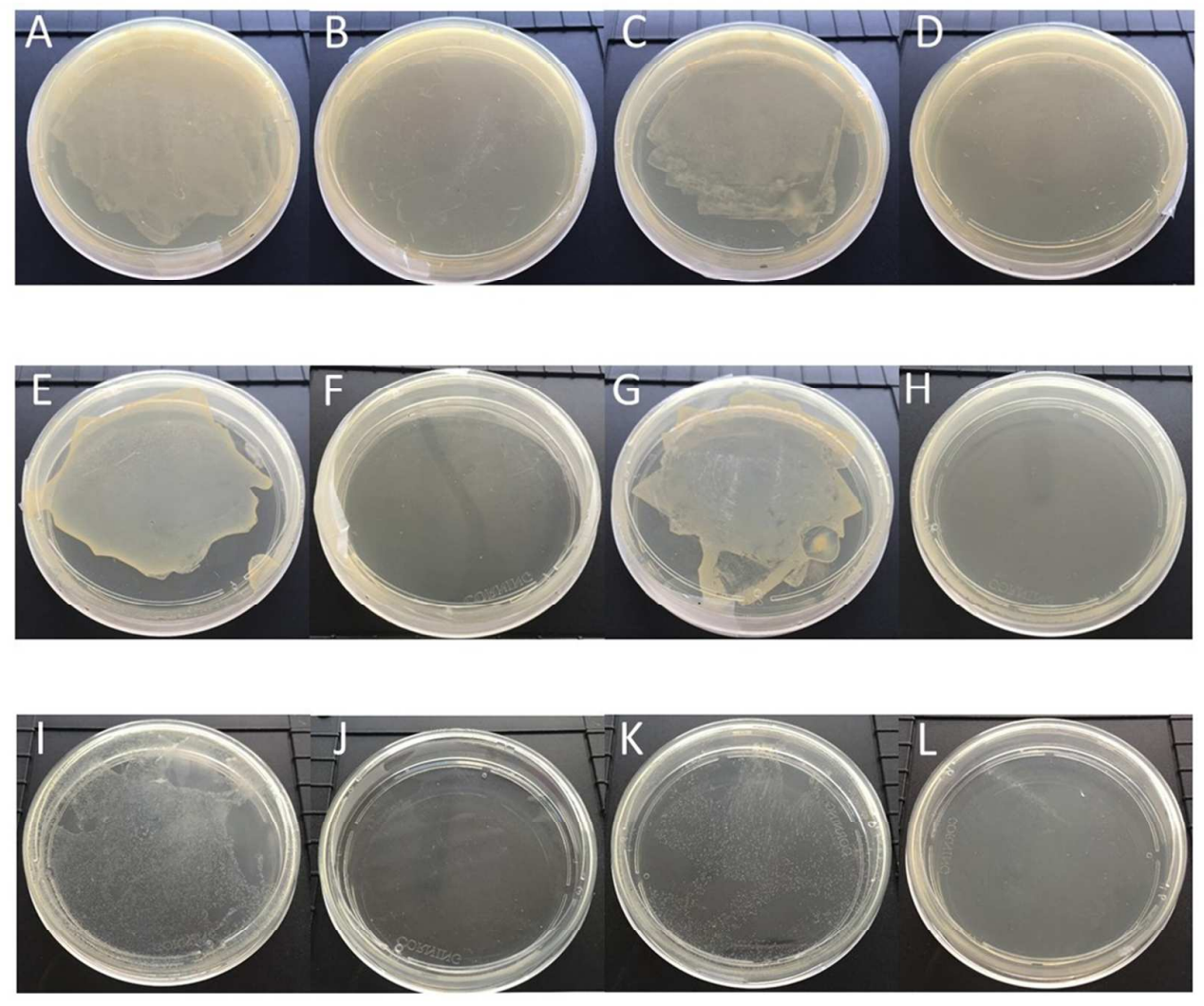

Figure S17 Aerobic plate count (APC) experiments to measure the deactivation efficiency by the electric treatment. Agar plates were prepared and inoculated with $150 \mathrm{uL}$ of different bacteria solutions before and after electric deactivation. (A) Untreated E. coli at the $\mathrm{OD}_{600}$ of 0.6. (B) Electrically treated E. coli at the $\mathrm{OD}_{600}$ of 0.6. (C) Untreated E. coli at the $\mathrm{OD}_{600}$ of 0.2. (D) Electrically treated E. coli at the $\mathrm{OD}_{600}$ of 0.2. (E) Untreated $S A U$ at the $\mathrm{OD}_{600}$ of 0.6. (F) Electrically treated $S A U$ at the $\mathrm{OD}_{600}$ of 0.6. (G) Untreated $S A U$ at the $\mathrm{OD}_{600}$ of 0.2. (H) Electrically treated $S A U$ at the $\mathrm{OD}_{600}$ of 0.2 . (I) Untreated E. coli which initial $\mathrm{OD}_{600}$ was 0.6 and diluted by 1000 times. (J) Electrically treated E. coli which initial $\mathrm{OD}_{600}$ was 0.6 and diluted by 1000 times. $(\mathrm{K})$ Untreated $S A U$ at the $\mathrm{OD}_{600}$ which initial $\mathrm{OD}_{600}$ was 0.6 and diluted by 1000 times. (L) Electrically treated $S A U$ which initial $\mathrm{OD}_{600}$ was 0.6 and diluted by 1000 times. 

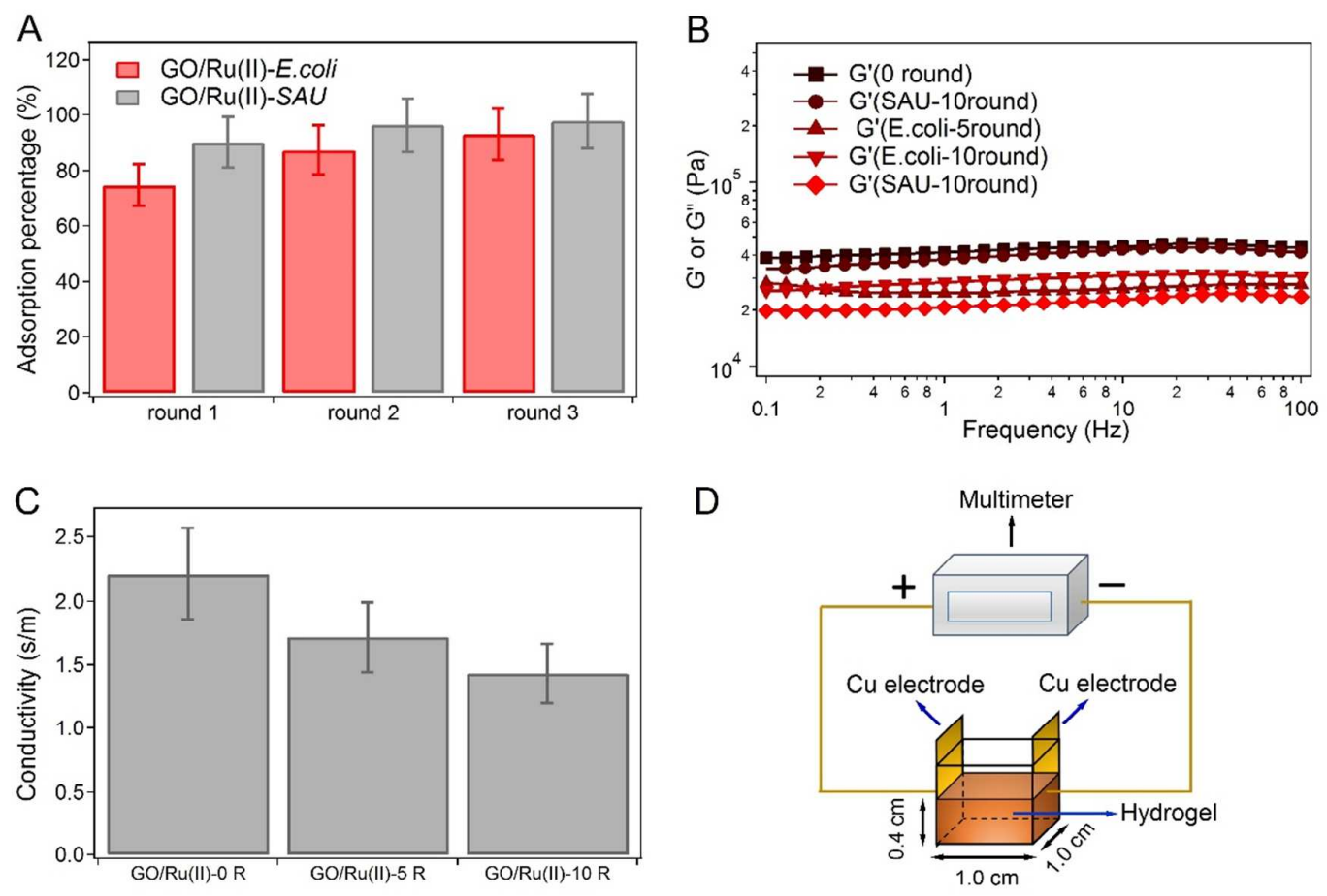

D

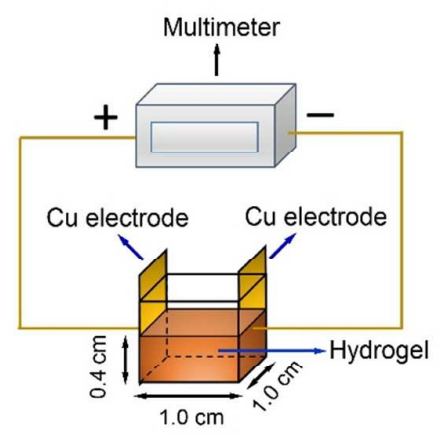

Figure S18. The reusability of the hydrogel for multiple runs of purification. (A) The accumulated bacteria removal efficiency during three runs of purification. (B) The mechanical properties of $\mathrm{GO} / \mathrm{Ru}(\mathrm{II})$ hydrogel after five and ten rounds of $E$. coli and $S A U$ adsorption. (C) The conductivities of $\mathrm{GO} / \mathrm{Ru}(\mathrm{II})$ hydrogel after 0,5 and 10 rounds of adsorption. (D) The schematic of the device used to measure the conductivity. The hydrogel was sandwiched between two copper layered electrodes and the volume of the hydrogel was $0.4 \mathrm{~mL}$. 
A

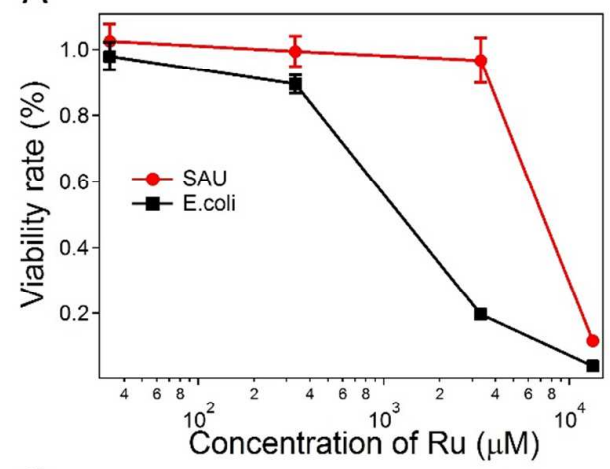

C

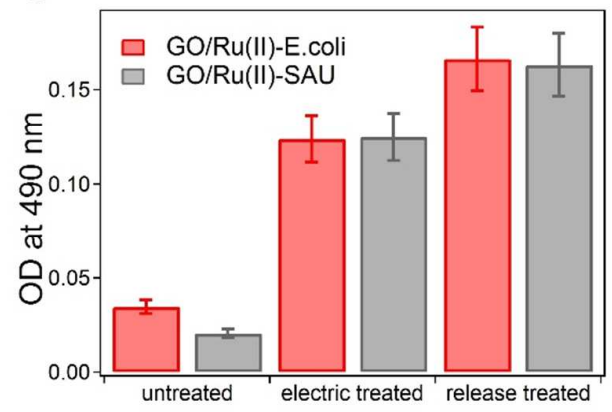

B

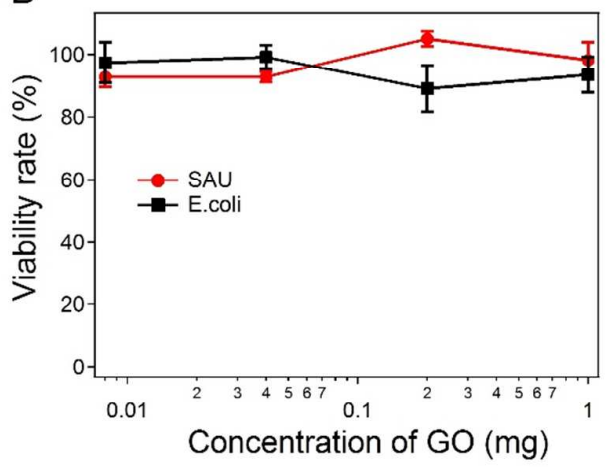

Figure S19. (A) The toxicity of Ru(II) complex to E. coli and $S A U$. (B) The toxicity of GO solution to E. coli and $S A U$. (C) The $\mathrm{LDH}$ release of untreated bacteria, electrically treated bacteria and bacteria treated with LDH releasing agent, in which LDH was fully released (label as release treated).
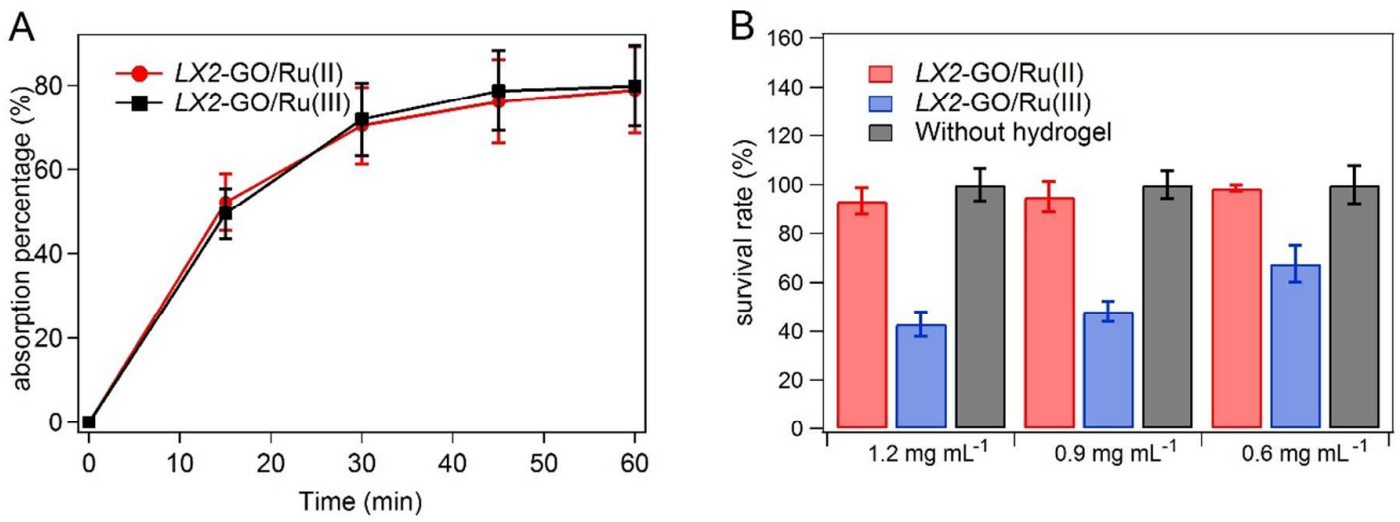
Figure S20 (A) The $L X 2$ adsorption kinetics for $\mathrm{GO} / \mathrm{Ru}(\mathrm{II})$ and $\mathrm{GO} / \mathrm{Ru}$ (III) hydrogels monitored by cell counting. (B) The survival rate of $L X 2$ cells with and without hydrogels.
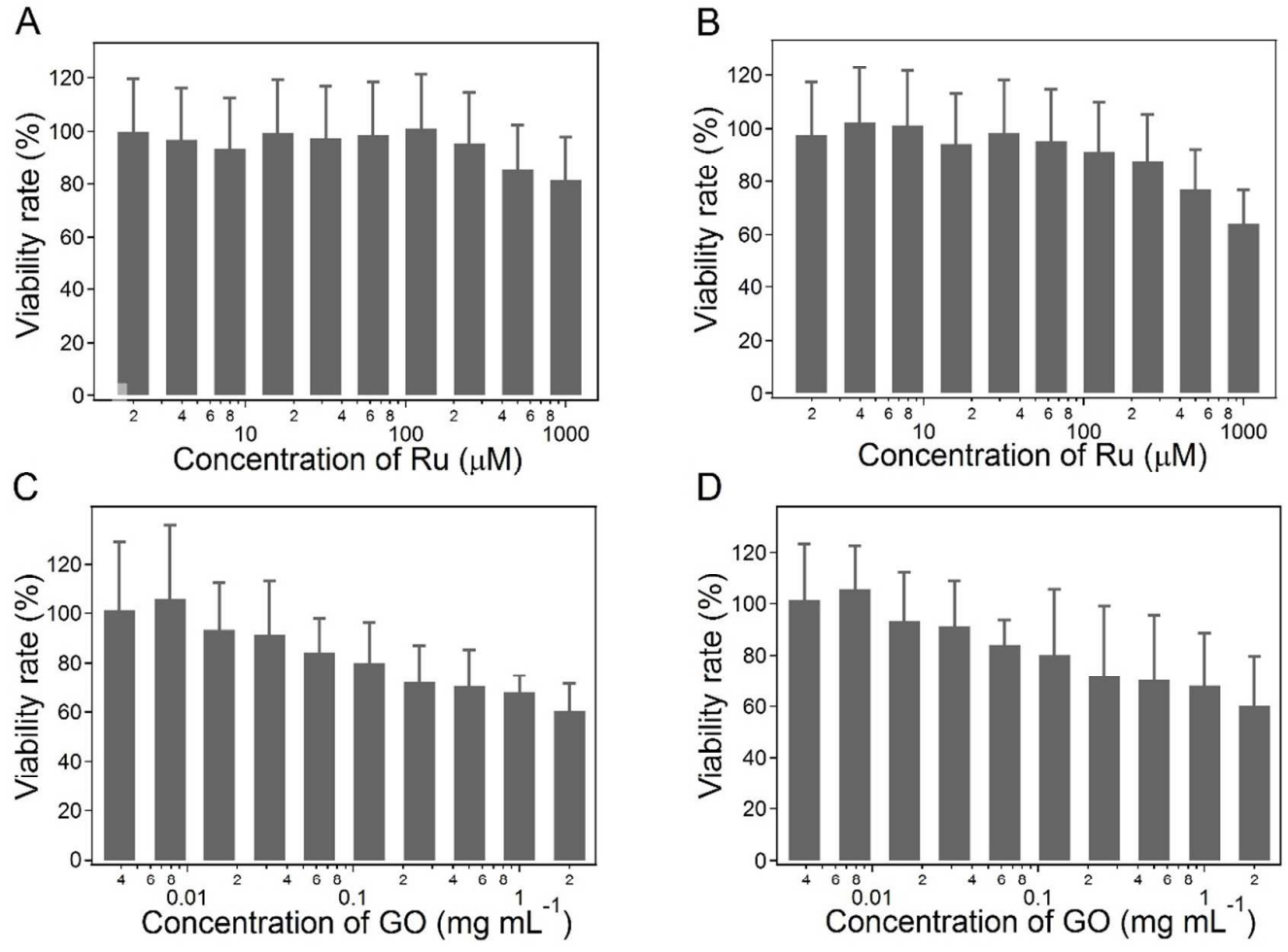

Figure S21. Cytotoxicity of $\mathrm{Ru}(\mathrm{II})$ and GO to cells. (A) The cytotoxicity of Ru (II) solution to $L X 2$. (B) The cytotoxicity of $\mathrm{Ru}(\mathrm{II})$ solution to $3 T 3$. (C) The cytotoxicity of GO solution to $L X 2$. (D) The cytotoxicity of GO solution to $3 T 3$. 

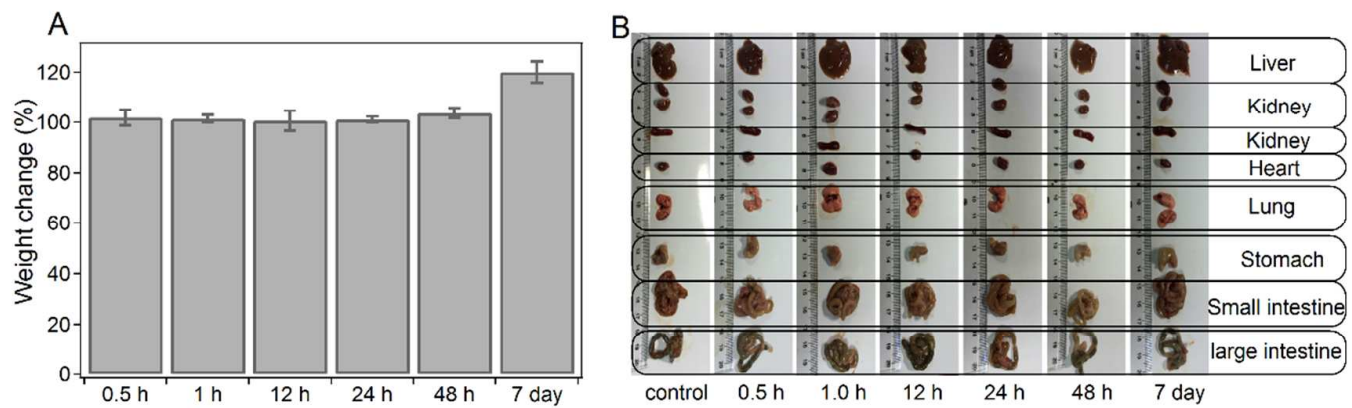

Figure S22. (A) The weight change of mice at different time points after feeding with the ruthenium complex. (B) The optical photos of mice organs for the control group and experimental groups. 